\title{
Feminismo y libertad. \\ Comentarios a los textos de Julia Varela y Fernando Álvarez-Uría
}

\section{M. ${ }^{a}$ Dolores Avia}

Universidad Complutense de Madrid

mariavia@psi.ucm.es

\section{Resumen}

En mi trabajo, hago unas reflexiones críticas sobre los textos de Julia Varela y Fernando Álvarez-Uría, autores que resaltan el papel de mujeres pioneras en el movimiento feminista español y de emancipación femenina. Comentando el texto de Varela, añado unos datos adicionales sobre otra mujer de la época, Mercedes Escribano, que comparte muchos rasgos con las mujeres que ella estudia. Sobre el texto de Álvarez-Uría, subrayo los aspectos diferenciales en el funcionamiento psicológico, interpersonal y social de mujeres y varones, un tema que él destaca. La coherencia entre las propuestas de los dos trabajos se destaca en el texto.

Palabras clave: movimiento feminista; anarquismo; emancipación de la mujer; España.

\section{Abstract. Feminism and Freedom: Comments on the Texts of Julia Varela and Fernando Álvarez-Uría}

In this paper, I make some critical comments about the contributions of Julia Varela and Fernando Álvarez-Uría in which they emphasize the role of pioneer women in Spanish feminism and the emancipation of women. In my comments to Varela's paper, I have added some biographical notes on a woman, Mercedes Escribano, who lived at the same time and shared many aspects with the women that she studies. My comments on ÁlvarezUría's text are based on the differential aspects of men and women in psychological, interpersonal and social functioning; a topic which he widely studies. The consistency among these two proposals is emphasized.

Keywords: feminist movement; anarchism; empowerment of women; Spain.

\section{Sumario}

Las aportaciones de las mujeres a una ética de nuestro tiempo

La política femenina alternativa
Oportunidades y desafíos de los movimientos anarquistas

Referencias bibliográficas 
Los escritos «Mujeres y política: La política de las mujeres en la España de la II República y la Guerra Civil», de Fernando Álvarez-Uría, y «Tres mujeres en lucha por la emancipación: Carmen Baroja y Nessi, Zenobia Camprubí Aymar y M. ${ }^{a}$ Teresa León Goyri», de Julia Varela, abordan una temática semejante, que desarrollan a partir del análisis de textos biográficos. En el caso de Julia Varela, los de las mujeres que figuran en el título; en el de Álvarez- Uría, los de Clara Campoamor, Victoria Kent, Dolores Ibárruri, Irene Falcón y Federica Montseny. Existe una gran coherencia en el planteamiento de ambos escritos, que culmina en algunas proposiciones que figuran al final de ellos y que tendré especial interés en comentar.

\section{Las aportaciones de las mujeres a una ética de nuestro tiempo}

El trabajo de Julia Varela ofrece un claro y lúcido análisis del movimiento de emancipación de la mujer, del que las tres elegidas son un buen exponente. Analiza ese proceso partiendo de los orígenes burgueses de las tres mujeres, a las que acertadamente, en un momento, denomina «dominantes dominadas», y estructura sus comentarios alrededor de tres apartados: el trabajo que realizan, su participación en redes solidarias femeninas y su implicación con las vanguardias artísticas y la cultura popular.

Este análisis del proceso de emancipación de las tres autoras, así como sus dificultades, me ha llevado a examinar, por cuestiones de semejanza y cercanía, el caso de una cuarta mujer que coincide, en muchas de las características señaladas por Varela, con la vida de las tres protagonistas de su escrito. Me refiero al caso de Mercedes Escribano Pérez, de origen social semejante al de ellas, con las que comparte el mismo contexto sociopolítico. Mujer universitaria, profesora en la Escuela Normal de Magisterio de Cuenca, de la que llegó a ser directora, esposa de intelectual, madre de familia y autora de numerosos poemas y cuentos infantiles, que dejó también abundante material autobiográfico (Muñoz Olivares, 2008). Como señala Julia Varela, en ese contexto, abundaban elementos de misoginia, fácilmente detectables en muchos intelectuales de la época (Marañón, Ramón y Cajal, Ortega, Benavente, Cansinos Assens, etc.) y que están presentes también en otros que produjeron un gran impacto en la cultura de su época y en las épocas venideras, como es el caso de Freud y Pavlov. Si se leen las Cartas a la novia, de Freud (1984), se puede ver cómo el tufo misógino aparece enseguida. De Pavlov, recuerdo haber leído, asimismo, en una carta a su futura mujer, que esperaba que ella tuviera tanta devoción por la casa como él la tenía por el laboratorio.

Mercedes Escribano estudió en Madrid, en la Escuela Superior de Magisterio, donde obtuvo el título equivalente al de licenciatura en Pedagogía, a la vez que su marido, Valentín Aranda, después inspector de enseñanza primaria, de quien fue compañera de promoción entre los años 1911 y 1914. Su vocación le habría llevado a estudiar Medicina, pero, como las tres autoras seleccionadas por Julia Varela, tuvo que enfrentarse a la oposición familiar, en este caso, la de su propio padre, hombre de izquierdas, original y aventurero, pero reticente a 
que su única hija pudiera seguir sus pasos y afrontar libremente su propia vida. Para cumplir el objetivo de matricularse en la universidad, tuvo que posponer sus planes y dedicarse un par de años a hacer de mujer de su casa y ama de llaves en las sucesivas viviendas de su padre, médico rural viudo que cambiaba frecuentemente de destino. Los planes del padre, como comenta en sus memorias, eran casarla con uno de sus pretendientes, pero ella se negó, aduciendo que lo suyo era seguir estudios superiores, que tuvo que sufragarse ella misma y que empezó cuando tenía 19 años. Fue allí donde conoció a su futuro marido, con el que inició una vida en la ciudad de Cuenca, donde obtuvo la cátedra de Geografía e Historia en la Normal de Magisterio, que desempeñó desde 1920 hasta 1940, año en el que recibió una sanción política que la apartó de su ciudad, de su casa y de los pilares sobre los que había sustentado toda su vida.

La actividad de Mercedes Escribano revela un afán de renovación pedagógica y un gran interés por los nuevos métodos de enseñanza, siguiendo los principios de la ILE. Durante unos años, coincide en su trabajo con Rodolfo Llopis, también catedrático de Geografía e Historia, posteriormente director general de Enseñanza Primaria. Con su esposo, organiza, en 1932, la Primera Semana Pedagógica Conquense (1932), que recibe la asistencia de Llopis y del entonces ministro de Instrucción Pública, Fernando de los Ríos, en la que imparte una conferencia que tiene un amplio eco en la prensa local, que reconoce y aplaude la utilización por parte de Mercedes de proyecciones de diapositivas en sus tareas pedagógicas, práctica muy novedosa en el momento (Escribano, 1932). Durante todos estos años, compartió su trabajo profesional con la casa (fue madre de cinco hijos), si bien en este segundo aspecto delegó a menudo en su cuñada y su suegra, con lo cual sacó un buen partido de una situación familiar que, aunque bien aceptada, le venía en cierto modo impuesta. Las dos mujeres, que se dedicaban a tareas tradicionales, hicieron de la casa su república, como dijo Luis Vives, mientras ella se refugiaba en su estudio, en el que preparaba sus clases, redactaba los Apuntes de Historia, que fueron varias veces reeditados y que desgraciadamente se han perdido, y trabajaba en el nuevo plan de formación de los docentes primarios, uno de los pilares más firmes de la República. Como las tres mujeres analizadas por Julia Varela, tuvo también una fina sensibilidad artística, que, en su caso, se plasmó en la escritura de poemas y cuentos infantiles (algunos de los cuales fueron ilustrados por el mayor de sus hijos, ver Muñoz Olivares, 2008) e impartió conferencias y cursillos (queda constancia de los realizados sobre Fray Luis de León). Tuvo una aguda conciencia social, enfocada muy especialmente a los niños más desfavorecidos, enfermos o víctimas en la primera parte de la contienda civil, a los que muchas veces se llevaba a su propia casa (el «capital altruista» al que se refiere Varela) y realizó múltiples actividades sociales, entre las que destacan la organización de roperos infantiles, la puesta en marcha del programa «La gota de leche» para ayudar a mujeres en la lactancia, la realización de escuelas de madres o su encendida defensa de las colonias escolares (García Salmerón, 2003). Colaboró frecuentemente en la prensa local con artículos de opinión, en los que firmaba siempre como «Una mujer», y dedicaba una atención espe- 
cial a la educación y a las obligaciones femeninas (ver Muñoz Olivares, 2008: 106-107), así como en revistas profesionales. Sólo recientemente, sin embargo, ha sido recopilada y publicada su obra literaria, formada por una novela y los cuentos y los poemas para niños y adultos señalados más arriba (Muñoz Olivares, 2008). Vemos, pues, un caso más de mujer singular que, frente a las pautas frecuentes entre sus contemporáneas, se esforzó por realizar sus deseos de autonomía y crecimiento personal, llevando a cabo un trabajo intelectual riguroso que, si bien limitado a un ámbito local, ejerció una amplia influencia en ámbitos profesionales. Al igual que las tres mujeres analizadas por Varela, también ella quedó frecuentemente «invisibilizada», en este caso, por la fuerte personalidad de su marido, que recibió más reconocimiento, aunque con frecuencia su trabajo fuera fruto del esfuerzo de ambos. No queda constancia, en cambio, de que, frente a las tres otras mujeres, Mercedes Escribano formara parte de redes femeninas que de alguna manera la ayudaran en su esfuerzo. Si las hubo, sus escritos no las reflejan.

\section{La política femenina alternativa}

Del trabajo de Fernando Álvarez-Uría, riguroso y bien escrito, señalaré especialmente un aspecto: el que supone la principal conclusión del mismo, en el que recoge las diferencias que observa entre el funcionamiento psicológico, social e interpersonal de las mujeres y los hombres.

Subraya Fernando, a partir del examen de sus cinco protagonistas femeninas, que las mujeres se muestran como más espirituales, y los hombres, más tendentes a una cultura material; que ellas se centran más en las relaciones sociales, mientras ellos destacan sus cualidades personales; ellas son más benevolentes que ellos en los juicios sobre los demás; siguen una política de cuidado, cuando ellos buscan preferentemente el prestigio personal. En suma, y quizá sea ésta la expresión más precisa de tales diferencias, ellas anteponen el nosotros al yo, al revés que ellos. Si hubiera que mencionar algunos calificativos para resumir tales diferencias, Álvarez-Uría elige para los varones los de fuerza, valentía o coraje, mientras que para las mujeres utiliza los de sensibilidad, piedad o búsqueda de la paz.

Este análisis ofrece una gran semejanza con algunos trabajos recientes de psicología cognitiva que revelan unas diferencias muy marcadas en la identidad de las personas, que ponen de manifiesto visiones autocéntricas o alocéntricas del yo (Markus y Kitayama, 1990). Cuando la investigación en este campo estaba dando por supuesto que las características cognitivas del yo individual estaban formadas por una serie de atributos personales autodefinitorios, básicamente coincidentes con los que Álvarez- Uría señala como característicos de los varones, la ampliación de la investigación a países orientales puso de manifiesto que tal visión sólo estaba presente en culturas individualistas occidentales, mientras que en culturas colectivistas, como las orientales y las de países menos desarrollados, como algunos de Centroamérica, predominaba una visión de uno mismo basada en el noso- 
tros, tal y como Fernando sugiere para las mujeres. Según aquellos estudios, los miembros de países individualistas tienen una visión del yo autocéntrica, en cambio, la de los países colectivistas es alocéntrica. He de reconocer que siempre que he tenido ocasión de comentar estos datos en mi trabajo didáctico, he añadido que, a mi juicio, el primer caso es más representativo de los varones y el segundo, de las mujeres, tal y como sugiere Álvarez-Uría. Pero no está solo: Victoria Camps, en su libro Virtudes públicas, señala una serie de características deseables de la identidad — responsabilidad, solidaridad, tolerancia- y discute posteriormente con amplitud la visión femenina y el grado en que estas cualidades están presentes en las mujeres (Camps, 1990). Revisa, asimismo, algunas posturas, como la de la psicóloga Carol Gilligan, que se refiere a la "ética de la justicia» frente a la "ética del cuidado", para contraponer, respectivamente, los puntos de vista del varón y los de la mujer, y, señalando el peligro de creer en dos éticas inconmensurables, con el cisma que ello supondría, acaba remarcando la conveniencia de una aportación femenina al discurso ético de nuestro tiempo.

En suma, los dos manuscritos, el de Álvarez-Uría y el de Varela, ofrecen, a partir de un trabajo basado en testimonios autobiográficos, un análisis certero y matizado de lo que supuso el proceso de emancipación femenina en nuestro pasado reciente, análisis que resulta muy oportuno y pertinente en este momento en el que, a pesar de los cambios experimentados y los indudables logros de las mujeres en el ámbito personal, familiar, laboral y social, aún se pueden percibir muchas de las actitudes a las que nuestras protagonistas tuvieron que enfrentarse. Yo también soy de las que cree que una visión femenina de los problemas y las soluciones sociales que se derivan de ella no pueden hacer más que enriquecernos y repercutir muy positivamente en nuestro futuro.

\section{Referencias bibliográficas}

CAmps, Victoria (1990). Virtudes públicas. Madrid: Espasa Calpe.

EsCribano, Mercedes (1932). «La geografía en la escuela», en Semana Pedagógica Conquense [existen referencias en las revistas La Opinión y El Centro].

FreUd, Sigmund (1984). Cartas a la novia. Barcelona: Tusquets.

García Salmerón, M.a Pilar (2003). Educación y República en Cuenca, 1931-1939. Cuenca: Diputación Provincial.

MarkUS, Hazel Rose y Kitayama, Shinobu (1990). «Culture and the self: Implications for cognition, emotion and motivation». Psychological Review, 98 (2), 224-253.

MuÑOz Olivares, Carmen (2008). Mercedes Escribano Pérez: Volviendo páginas de mi vida. Cuenca: Diputación Provincial.

Semana Pedagógica Conquense (1932). Cuenca: Imprenta Artística. 

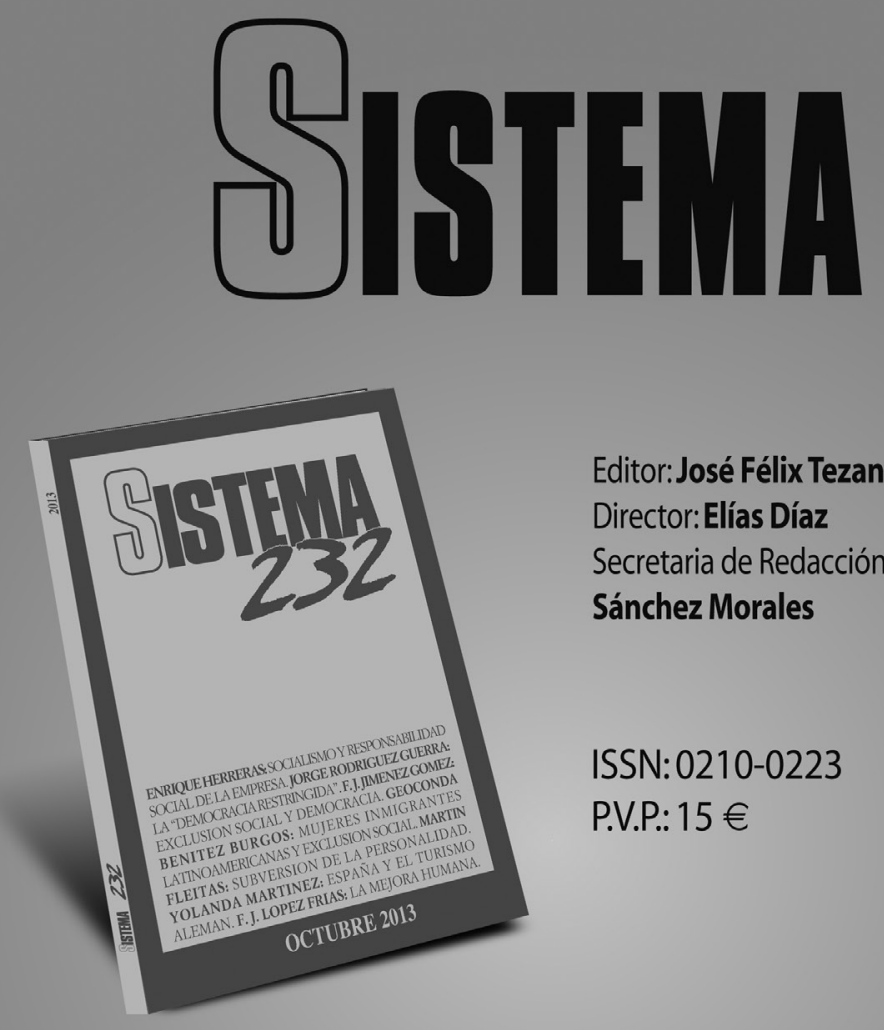

Editor:José Félix Tezanos

Director: Elías Díaz

Secretaria de Redacción:María Rosario

Sánchez Morales

ISSN:0210-0223

P.V.P.: $15 €$

Enrique Herreras: Socialismo y responsabilidad social de la empresa.

Jorge Rodríguez Guerra: La "Democracia restringida".

F. J.Jimenez Gómez: Exclusión social y democracia.

Geoconda Benitez Burgos: Mujeres inmigrantes latinoamericanas y exclusión social.

Martín Fleitas: Subversión de la personalidad.

Yolanda Martínez: España y el turismo alemán.

F. J.López Frías: La mejora humana.

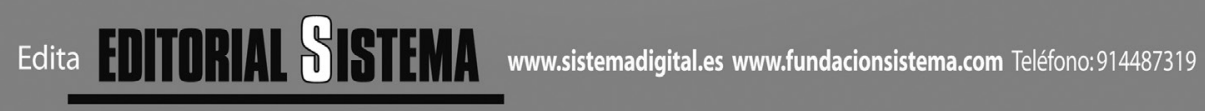

